\title{
Functional Neuroanatomy of Contextual Acquisition of Concrete and Abstract Words
}

\author{
Anna Mestres-Missé ${ }^{1 *}$, Thomas F. Münte ${ }^{2}$, \\ and Antoni Rodriguez-Fornells ${ }^{1,3}$
}

\begin{abstract}
The meaning of a novel word can be acquired by extracting it from linguistic context. Here we simulated word learning of new words associated to concrete and abstract concepts in a variant of the human simulation paradigm that provided linguistic context information in order to characterize the brain systems involved. Native speakers of Spanish read pairs of sentences in order to derive the meaning of a new word that appeared in the terminal position of the sentences. fMRI
\end{abstract}

\section{INTRODUCTION}

To build a theory of the representation of concrete and abstract words ${ }^{1}$ it may be helpful to consider how these different types of words are learned. Children's first vocabularies comprise mostly concrete words, as they are restricted to the information that is accessible through sensory experience with the material world (Bloom, 2000; Gillette, Gleitman, Gleitman, \& Lederer, 1999). Abstract word concepts are acquired through their use in sentences and their relationship to other concepts with little or no physical support (Bloom, 2000). Thus, abstract words cannot be learned until a certain representational capacity is reached that permits the utilization of linguistic contexts in order to define the meaning of these words (Bloom, 2000). It has been proposed on the basis of neuropsychological and neuroimaging evidence (see below) that there might be a relationship between the manner in which these words are learned and the format in which they are stored (Martin, Ungerleider, \& Haxby, 2000; Saffran \& Sholl, 1999). Whereas abstract concepts appear to be stored in a propositional representational format, concrete words might be represented in auditory, visual, tactile, and sensorimotor formats.

\footnotetext{
${ }^{1}$ University of Barcelona, Spain, ${ }^{2}$ Otto von Guericke University, Magdeburg, Germany, ${ }^{3}$ Institució Catalana de Recerca i Estudis Avançats (ICREA), Barcelona, Spain

*Currently at the Department of Neuropsychology, Otto von Guericke University.
}

revealed that learning the meaning associated to concrete and abstract new words was qualitatively different and recruited similar brain regions as the processing of real concrete and abstract words. In particular, learning of new concrete words selectively boosted the activation of the ventral anterior fusiform gyrus, a region driven by imageability, which has previously been implicated in the processing of concrete words.

\section{Behavioral, Neuropsychological, and Neuroimaging Evidence}

From behavioral studies, it has been demonstrated that concrete words have a processing advantage over abstract words (concreteness effect). Typically, abstract words are processed more slowly (Kroll \& Merves, 1986; Schwanenflugel \& Shoben, 1983), remembered worse (Paivio, 1971), and take longer to read (Schwanenflugel \& Stowe, 1989; Schwanenflugel \& Shoben, 1983) than concrete words.

Several neuropsychological studies have provided evidence for dissociations between the representation of abstract and concrete concepts that may reflect qualitative differences in their acquisition and representational format (Crutch \& Warrington, 2005). For example, numerous neuropsychological case studies have shown an amplified concreteness effect after brain damage (Martin \& Saffran, 1992; Katz \& Goodglass, 1990; Coltheart, Patterson, \& Marshall, 1980; Goodglass, Hyde, \& Blumstein, 1969). Besides, there are also several reports of patients who showed a reversal of the concreteness effect (Marshall, Pring, Chiat, \& Robson, 1996; Breedin, Saffran, \& Coslett, 1994; Warrington \& Shallice, 1984; Warrington, 1975, 1981). These patients are characterized by selective impairment for concrete words while showing a relative preservation of abstract words.

This double dissociation of concrete and abstract word processing suggests that the brain regions that sustain concrete and abstract words representations might be different as well. These lesions in different regions which 
produce impairment of different types of words led Allport (1985) to propose that the features and properties which form the representation of a concept are distributed over different subsystems directly related to the domain (visual, auditory, tactile) through which the information was acquired. In support of Allport's model, the loss of perceptual aspects of word meaning has been found to cause the reversed concreteness effect (Marshall et al., 1996; Breedin et al., 1994).

Functional imaging studies have also provided evidence for the implication of different brain regions in the processing of concrete and abstract words. The processing of abstract words has been associated with greater activation in areas such as the middle and superior temporal gyrus and the left inferior frontal gyrus (IFG), which are thought to be involved in semantic processing (Pexman, Hargreaves, Edwards, Henry, \& Goodyear, 2007; Fliessbach, Weis, Klaver, Elger, \& Weber, 2006; Binder, Westbury, McKiernan, Possing, \& Medler, 2005; Sabsevitz, Medler, Seidenberg, \& Binder, 2005; Wallentin, Ostergaard, Lund, Ostergaard, \& Roepstorff, 2005; Fiebach \& Friederici, 2004; Noppeney \& Price, 2004; Whatmough, Verret, Fung, \& Chertkow, 2004; Grossman et al., 2002; Friederici, Opitz, \& von Cramon, 2000; Jessen et al., 2000; Wise et al., 2000; Kiehl et al., 1999; Perani et al., 1999; Mellet, Tzourio, Denis, \& Mazoyer, 1998). By contrast, concrete words show greater activity in regions associated with higher levels of visual processing, such as the ventral anterior part of the fusiform gyrus (Bedny \& Thompson-Schill, 2006; Fliessbach et al., 2006; Sabsevitz et al., 2005; Wallentin et al., 2005; Fiebach \& Friederici, 2004; Giesbrecht, Camblin, \& Swaab, 2004; Whatmough et al., 2004; Wise et al., 2000; Mellet et al., 1998; D'Esposito et al., 1997; Fletcher et al., 1995). However, other studies have failed to find greater activations for concrete words in these areas (e.g., Binder et al., 2005; Jessen et al., 2000) or in any other brain regions (Noppeney \& Price, 2004; Friederici et al., 2000; Kiehl et al., 1999; Krause et al., 1999; Perani et al., 1999).

\section{Theoretical Proposals for the Concreteness Effects}

Several theories have been proposed to account for the concreteness effect. The dual-coding theory (Paivio, 1971, 1986) proposes that there are two cognitive symbolic systems, an "imagery" system specialized for the representation and processing of nonverbal objects/events and a "verbal system" dealing with linguistic representations. The nonverbal symbolic system is composed of modalityspecific internal structures (visual, auditory, haptic, and motor) that map onto the sensorimotor attributes of the represented objects. This subsystem has some similarities with the more recent proposal of perceptual symbol systems, which can construct specific simulations (similar to a mental image) of an entity or event using repre- sentations derived from perceptual-motor experiences (Barsalou, 1999). According to this qualitative account, the main difference between concrete and abstract words is that image representations are stored only for concrete words. Whereas abstract words predominantly activate verbal representations, the processing of concrete words coactivates linguistic and imagery (sensorimotor) representations leading to facilitated processing of concrete words.

In contrast to this view, the context availability theory (Schwanenflugel \& Shoben, 1983) argues that the difference between concrete and abstract words is only quantitative. When presented in isolation, concrete words are thought to activate more contextual information in semantic memory than abstract words (Schwanenflugel \& Stowe, 1989; Schwanenflugel \& Shoben, 1983) because the latter tend to appear within a wider range of contexts and are, therefore, less likely to recruit specific pieces of information, and thus, are more difficult to process (Schwanenflugel \& Shoben, 1983). This processing disadvantage disappears if abstract words are presented within a context, such as a sentence. This is in agreement with the idea that concrete words are characterized by more context-dependent properties, whereas abstract words have more context-independent properties (Barsalou, 1982). Another quantitative account of the concreteness effect postulates that it arises from the fact that concrete words are supported by more semantic features than abstract words (Plaut \& Shallice, 1993). This hypothesis agrees with previous findings which showed that normal participants produced more associates for concrete than abstract words (de Groot, 1989).

The three theoretical approaches agree that the representation of concrete concepts entails some additional component that facilitates access, activation, and further remembering, but differ in their explanation of the nature of this component. Furthermore, the dual-coding and the context availability theories have difficulties in explaining the reversal of the concreteness effect in certain neurological patients. In fact, the loss of the additional component that gives concrete words a processing advantage should level the difference between concrete and abstract words, which is clearly not the case in some patients. However, Paivio (2006) has recently argued that damage to perceptual components of word meaning in previous patients (Breedin et al., 1994) might be the key to understanding the reversal of the concreteness effect in the context of the dual-coding theory. The possible disruption of normal imaginary processes and/or their respective association with their verbal and well-preserved representations might predict impoverished concrete word processing. Furthermore, whereas certain "lesions" to a connectionist model of deep dyslexia developed by Plaut and Shallice (1993) lead to a selective impairment of concrete words, this model does not account for the most fundamental distinction between concrete and abstract words, that is, 
the perceptual properties which are essential for the representation of concrete but not abstract words (Breedin et al., 1994).

\section{Objectives}

As there is no previous neuroimaging evidence on the learning of concrete and abstract new words, we investigated the neurophysiological correlates underlying learning new words, and how these are modulated by word concreteness. As a working hypothesis, we predicted that the same regions that store the representation of concrete and abstract words and its semantic features (see above) will support the association of new words to their appropriate concepts. To test this hypothesis, a new word learning task was used in which adults were engaged in discovering the meaning of new concrete and abstract words presented repetitively across several sentences (Mestres-Missé, Rodriguez-Fornells, \& Münte, 2007). Notice, however, that the meanings corresponding to the new words already exist in the learner's semantic memory. Thus, the present contextual learning task mimics the process of learning the meaning of a new word in a foreign language. This process of inferring meanings from contexts is very important not only in second-language research but also in first-language acquisition, where it is supposed to be the principal source of learning of new words in school (Nation, 2001). In the present experiment, differences in learning concrete and abstract words from context were studied in adults using a variant of the human simulation paradigm of vocabulary learning (Gillette et al., 1999). Finally, the paradigm was also designed to control for the amount of contextual information provided for learning each type of new words.

\section{METHODS}

\section{Participants}

Fifteen native Spanish speakers ( 9 women, mean age $=$ $23.6 \pm 3$ years) without a history of neurological or psychiatric disease were enrolled. All participants were right-handed according to the Edinburgh Handedness Scale and gave written informed consent. The study was approved by the ethical committee of the University of Magdeburg.

\section{Stimuli and Tasks}

While in the scanner, participants silently read pairs of sentences. In the critical conditions, the two sentences ended in a new word (standing for either an abstract word, henceforth Nwa for new-word abstract, or a concrete word, henceforth Nwc for new-word concrete) and participants had to discover the meaning of the hidden word. Hidden words were nouns of medium frequency.
In addition, as a control, sentence pairs ending in existing concrete (Rwc for real-word concrete) or abstract (Rwa for real-word abstract) words were also presented. An example for the $N w c$ condition (all materials were in Spanish, examples are translated) was:

1. "She likes people with nice and clean tankies"

2. "After the meals you should brush your tankies" Hidden word: teeth.

An example for the Nwa condition was:

1. "She didn't want to tell me her golmet"

2. "Don't tell this to anybody, it is a golmet" Hidden word: secret.

Sentences were systematically counterbalanced across the two critical conditions by creating different sentence lists. Sentences uniformly had a length of eight words. New words respected the phonotactic rules of Spanish and were created by changing one or two letters of an existing word.

The hidden words were 80 concrete words and 80 abstract words (see Appendices A and B for the complete list). Concrete words were selected from previous wordlearning experiments (Mestres-Missé et al., 2007) (mean frequency of 62.7 per million occurrences) (SebastianGallés, Martí, Carreiras, \& Cuetos, 2000). Moreover, all of the selected words were highly imaginable, concrete, and familiar, as rated on scales ranging from 1 (low) to 7 (bigh); mean familiarity was 6.3, mean imageability was 6.2, and mean concreteness was 5.9. Abstract words were matched on frequency with concrete words (mean frequency of 65.6 per million occurrences). The selected abstract words were highly familiar, and low in imageability and concreteness (mean familiarity: 5.9; mean imageability: 3.3, and mean concreteness: 3.6).

Two lists of 160 sentence pairs were created (320 sentences per list). Each list comprised 40 new-word abstract (Nwa) sentence pairs, 40 new-word concrete (Nwc) sentence pairs, 40 real-word abstract (Rwa) sentence pairs (control condition), and 40 real-word concrete (Rwc) sentence pairs (control condition). Concrete sentences were chosen from previous word-learning experiments (Mestres-Missé et al., 2007). The cloze probability of each sentence was assessed in pilot studies. The cloze probability of a word in a given context refers to the proportion of people who would choose to complete that particular sentence fragment with that particular word (Taylor, 1953). Mean cloze probability for the final pool of concrete sentences was: first sentence (low constraint) $15.6 \%(S D=13.6)$ and second sentence (high constraint) $85.8 \%(S D=8.4)$. The probability of meaning discovery after reading both sentences sequentially was 97.6\% ( $S D=3.8)$. Abstract sentences were built and tested in the same way as concrete ones (Mestres-Missé et al., 2007). Mean cloze probability for the final pool of 
abstract sentences was: first sentence (low constraint) $12.7 \%(S D=11.5)$ and second sentence (high constraint) $86.5 \%(S D=11.3)$. The probability of meaning discovery reading both sentences sequentially was $94.5 \%(S D=6.6)$.

The two lists were matched in frequency, familiarity, concreteness, and imageability for the hidden word; abstract words were matched to abstract words and the same for concrete words. Furthermore, frequency was matched between lists across all word types. The assignment of the experimental condition (Nwc, Nwa, Rwc, Rwa) was systematically rotated across the four groups of 40 sentence pairs in the two lists created. For the Rwc and Rwa conditions, the sentences were presented with the appropriate real word in the terminal position. Contexts were rotated systematically over real and new words for concrete and abstract conditions separately. This procedure ensures that, across the group of participants, each context occurred equally often in conjunction with real or new words. Each list of 160 sentence pairs was divided into eight experimental runs comprising five sentence pairs per condition as well as five additional fixation trials of $8 \mathrm{sec}$.

Each run started with four baseline images ( $8 \mathrm{sec}$ ) to allow the magnetic resonance signal to reach equilibrium. Each trial began with a fixation cross lasting $500 \mathrm{msec}$, then sentence stems (seven words) were presented centrally for 2000 msec. After a variable interval between 1 and $2 \mathrm{sec}$, the terminal words or new words were presented for $500 \mathrm{msec}$. After a variable interval of 1 to $6 \mathrm{sec}$ during which the screen remained dark, the second sentence was presented in the same fashion. After the second sentence, participants were required to think about the hidden word or, in the case of a real word, about a semantically related word. The order of the four experimental conditions within an experimental run was pseudorandomized, with the restriction that the same condition could not occur more than two times in a row. Stimulus presentation was controlled by Presentation 9.20 software (Neurobehavioral Systems) and synchronized with MRI data acquisition with an accuracy of 1 msec. Stimuli were presented in white on a black background and projected onto a screen and could be viewed by the participant through a mirror system mounted onto the head coil.

Prior to the scanning session, participants were carefully trained outside the scanner using test trials to ensure that they fully understood the task. Scanning began with a 15-min structural scan followed by the eight experimental runs, each lasting about $7 \mathrm{~min}$. A short rest was given between runs.

As the fMRI design did not allow direct testing for correct meaning assignment, a short behavioral twoalternative forced-choice task was performed during breaks between functional runs. Participants were shown a new word together with a correct or an incorrect word. The correct word referred to the meaning that participants had to discover in the learning task. The incorrect word referred to the meaning of another new word that had appeared in the same learning run. These stimuli were presented visually in a pyramid arrangement with the new word positioned at the top center of the display and two word choices (actual meaning of the new wordmeaning of another new word) on either side of the bottom of the display. Participants indicated the appropriate meaning for the particular new word by pressing one of the two buttons (10 trials after each block; random SOA of 1000-2000 msec). Subsequently, participants performed an old/new-word recognition task, in which 20 words were presented ( 5 from the Rwa and 5 from the Rwc condition, and 10 new real words), and the participants had to indicate by pressing one of two buttons whether they had seen a particular word in the preceding block. This task served to induce participants to attend to the Rwc and Rwa sentences (which otherwise could have been neglected).

After the scanning session, a new-word recognition test was carried out. Participants were presented with a list of 160 new words (80 learned new words, half concrete and half abstract, and 80 fillers) with the participants' task being to mark those new words that had occurred during the scanning session and to recall their meaning. Data from only 14 participants were collected for this test.

\section{fMRI Data Acquisition}

Images were acquired on a 3-T whole-body MRI system (Siemens Magnetom Trio, Erlangen, Germany). Wholebrain T2*-weighted fMRI images were obtained (200 scans per run) using axially oriented echo-planar imaging ( $\mathrm{TR}=$ 2 sec; $\mathrm{TE}=30 \mathrm{msec}$; flip angle $=80^{\circ} ; 32$ slices; 4- $\mathrm{mm}$ thickness; no gap; matrix size $=64 \times 64$; field of view $=$ $224 \mathrm{~mm}$; resolution $=3.5 \times 3.5 \times 4 \mathrm{~mm}^{3}$ ). The first four volumes of each session were discarded owing to T1 equilibration effects. For anatomical reference, a highresolution T1-weighted anatomical image was obtained (magnetization-prepared, rapid-acquired gradient echoes [MPRAGE], TR $=2500 \mathrm{msec} ; \mathrm{TE}=4.77 \mathrm{msec}$; TI $=$ 1100 msec; flip angle $=7^{\circ} ; 192$ slices; $1 \mathrm{~mm}^{3}$ isotropic voxels). The sentences were back-projected on a screen mounted on the head coil, allowing the participants to read them through a mirror.

\section{fMRI Data Preprocessing}

Data were analyzed using standard procedures implemented in SPM2 (www.fil.ion.ucl.ac.uk/spm). First, functional volumes were phase-shifted in time with reference to the first slice to minimize purely acquisition-dependent signal variations across slices. Head-movement artifacts were corrected based on an affine rigid body transformation, where the reference volume was the first image of the first run (e.g., Friston, Williams, Howard, Frackowiak, \& Turner, 1996). Functional data were then averaged and 
the mean functional image was normalized to a standard stereotactic space using the EPI-derived MNI template (ICBM 152, Montreal Neurological Institute) provided by SPM2. After an initial 12-parameter affine transformation, an iterative nonlinear normalization was applied using discrete cosine basis functions by which brain warps are expanded in SPM2 (Ashburner \& Friston, 1999). Resulting normalization parameters derived for the mean image were applied to the whole functional set. Finally, functional EPI volumes were resampled into $4 \mathrm{~mm}^{3}$ voxels and then spatially smoothed with an 8-mm full-width halfmaximum isotropic Gaussian kernel to minimize effects of intersubject anatomical differences.

\section{fMRI Data Analysis}

The statistical evaluation was based on a least-square estimation using the general linear model by modeling the different conditions with a regressor waveform convolved with a canonical hemodynamic response function (Friston, Josephs, Rees, \& Turner, 1998). Specifically, the event-related design matrix included all conditions of interest, that is, first sentence new-word concrete (1Nwc; new-word concrete embedded in the first-sentence context) and, analogously, 2Nwc (new-word concrete second sentence), 1Nwa (new-word abstract first sentence), 2Nwa, 1Rwc, 2Rwc, 1Rwa, 2Rwa. The data were high-pass filtered (to a maximum of $1 / 128 \mathrm{~Hz}$ ), and serial autocorrelations were estimated using an autoregressive model [AR(1) model]. Resulting estimates were used for nonsphericity correction during model estimation. Confounding effects in the global mean were removed by proportional scaling, and signal-correlated motion effects were minimized by including the estimated movement parameters. Contrast images were calculated for each subject. The individual contrast images were entered into a secondlevel analysis using a one-sample $t$ test.

The main contrasts were defined as follows:

(i) Real-word analysis:

Word exposure effect: $(1 \mathrm{Rwc}+1 \mathrm{Rwa})>(2 \mathrm{Rwc}+$ 2Rwa) for first-sentence effect (reverse for second sentence).

Imageability effect: $(1 \mathrm{Rwc}+2 \mathrm{Rwc})>(1 \mathrm{Rwa}+$ 2Rwa) for concrete word effect (reverse for abstract word)

(ii) New-word analysis:

Word exposure effect: $(1 \mathrm{Nwc}+1 \mathrm{Nwa})>(2 \mathrm{Nwc}+$ $2 \mathrm{Nwa}$ ) for first-sentence effect (reverse for second sentence).

Imageability effect: $(1 \mathrm{Nwc}+2 \mathrm{Nwc})>(1 \mathrm{Nwa}+$ $2 \mathrm{Nwa}$ ) for concrete new-word effect (reverse for abstract new-word effect). (iii) Real-word vs. New-word comparison (at the secondsentence presentation):

Word-type effect: $(2 \mathrm{Rwc}+2 \mathrm{Rwa})>(2 \mathrm{Nwc}+$ $2 \mathrm{Nwa}$ ) for real-word effect (reverse for new-word effect).

Imageability effect: $(2 \mathrm{Rwc}+2 \mathrm{Nwc})>(2 \mathrm{Rwa}+$ 2Nwa) for concrete word effect (reverse for abstract word effect).

The corresponding interactions between the different factors (Word exposure $\times$ Imageability for $\mathrm{Rw}$ and $\mathrm{Nw}$ conditions, and Word Type $\times$ Imageability in the comparison between Rw and Nw conditions) were calculated accordingly. Unless mentioned otherwise, contrasts were thresholded at $p<.001$ with a cluster extent of more than 20 contiguous voxels, and only clusters with a significant $p<.05$, corrected for multiple comparisons, are reported and interpreted (Worsley \& Friston, 1995). The maxima of suprathreshold regions were localized by rendering them onto the volunteers' mean normalized T1 structural images on the MNI reference brain (Cocosco, Kollokian, Kwan, \& Evans, 1997). Maxima and all coordinates are reported in MNI coordinates as used by SPM and labeled according to the Talairach atlas.

Finally, a parameter estimate analysis was conducted to determine more precisely the relationship between the observed activations and learning concrete and abstract new words. Maps of parameter estimates ( $\beta$ values) were computed from the generalized linear model to assess the magnitude of activation during each condition. The mean parameter estimate of each regressor was then calculated at the cluster activation maximum for each participant and region. These mean parameter estimates values in each condition and region were then averaged across participants. These values were used as dependent variables in two-way repeated measures ANOVAs conducted separately for new-word and realword conditions with the following factors: word exposure (first vs. second sentence) and imageability (concrete vs. abstract). Further statistical analyses with planned comparisons (two-sided, paired-sample $t$ tests) were used to test differences $(p<.05)$ between the parameter estimates from the different conditions.

\section{RESULTS}

\section{Behavioral Performance}

Meaning recognition for Nwc and Nwa did not differ significantly $(71 \pm 15.3 \%$ vs. $65 \pm 15.1 \%$, respectively, $t=$ 1.96, $p=.069$ ) and was significantly different from chance $[$ Nwc: $t(14)=17.93, p<.0001$; Nwa: $t(14)=$ $16.65, p<.0001]$. Although the false alarm rate did not differ (Nwc: $21.1 \pm 10.8 \%$ vs. Nwa: $24.2 \pm 10.6 \%, t=$ $-1.2, p=.24)$, fewer omissions were observed for Nwc $[7.9 \pm 7.8 \%$ vs. $10.7 \pm 8.5 \%, t(14)=-2.2, p<.044]$. 
Reaction times (RTs) were significantly shorter for Nwc $[1674 \pm 187 \mathrm{msec}$ vs. $1809 \pm 233 \mathrm{msec}, t(14)=-3.38$, $p<.004$ ], which may explain the higher omission rate for abstract new words, as an RT deadline of $3000 \mathrm{msec}$ was used.

In the old/new-word recognition task the overall hit rate was $85.1 \%(S D=13.1)$ and false alarms occurred in $10.8 \%(S D=11.3)$, indicating that participants paid attention to the real-word sentence conditions. No differences between concrete and abstract words were found for hits (Rwc: $86 \pm 14.7 \%$, Rwa: $84.2 \pm 12.8 \%$; $t<1$ ), false alarms (Rwc: $10.5 \pm 13.7 \%$, Rwa: $11.1 \pm 10 \%$; $t<$ 1) and omitted responses (Rwc: $3.7 \pm 4 \%$, Rwa: $4.7 \pm$ $4.8 \% ; t<1)$. However, participants were faster to judge concrete words [Rwc: $1188 \pm 202$ msec; Rwa: $1365 \pm$ 206 msec, $t(14)=-5.2, p<.0001]$.

In the new-word recognition test carried out after the scanning session, participants correctly recognized 13.4 $(S D=7.4)$ of $40 \mathrm{Nwc}$ and $11.6(S D=7.8)$ of $40 \mathrm{Nwa}(t=$ $1.5, p=.14)$. Of those new words correctly recognized, meaning was correctly recalled only for $3.5(S D=2.8)$ concrete and $1.9(S D=2.8)$ abstract new words $[t(13)=$ $2.70, p<.018]$.

\section{fMRI Data}

\section{Real-word Analysis}

The contrast first-sentence real word versus secondsentence real word (word exposure effect) yielded acti- vations in the left fusiform gyrus (Brodmann's area [BA] 37), visual word form area (VWFA), right middle occipital gyrus (BA 18), left cuneus (BA 17), right precuneus/ superior parietal lobe (BA 7), left IFG (BA 45), right inferior/middle frontal gyrus (BA 45/46), and left middle temporal gyrus (BA 21) (Table 1, Figure 1A). There were no areas with significant activation for the opposite contrast. This pattern is consistent with the repetitive suppression phenomenon (Grill-Spector, Henson, \& Martin, 2006; Wheatley, Weisberg, Beauchamp, \& Martin, 2005) due to priming on the second occurrence of the word (Ganel et al., 2006; Schacter, Dobbins, \& Schnyer, 2004; Dehaene et al., 2001; Wiggs \& Martin, 1998).

Regarding the imageability effect, neither for the contrast Rwc > Rwa nor for the opposite contrast did significant activations emerge at the chosen threshold. However, when the threshold was lowered $(p<.005$, cluster extent 20 voxels), a significant activation was revealed in the right middle temporal gyrus (BA 21; coordinates: $52,-24,-8 ; t=4.02, p<.005)$ for the latter contrast. No significant interaction was found between word exposure and imageability.

\section{New-word Analysis}

The contrast first-sentence new word versus secondsentence new word (word exposure effect) did not yield any significant activation. The opposite contrast showed significant activation in the left claustrum, left middle

Table 1. Activation Clusters for Main Effects (Word Exposure and Imageability) and Interaction on Real Words

\begin{tabular}{|c|c|c|c|c|c|c|}
\hline \multirow[b]{2}{*}{ Brain Region } & \multirow[b]{2}{*}{$\sim B A$} & \multicolumn{4}{|c|}{ Coordinates } & \multirow[b]{2}{*}{ p Corrected } \\
\hline & & $x$ & $y$ & $z$ & $t$ & \\
\hline \multicolumn{7}{|l|}{ Word Exposure Effect $(1 \mathrm{Rw}>2 \mathrm{Rw})$} \\
\hline L Fusiform gyrus & 37 & -36 & -52 & -20 & 8.89 & $.0001^{*}$ \\
\hline R Middle occipital gyrus & 18 & 24 & -96 & 0 & 7.53 & $.0001^{*}$ \\
\hline L Cuneus (SCA) & 17 & -12 & -88 & 0 & 6.45 & $.0001^{*}$ \\
\hline R Precuneus/superior parietal lobe & 7 & 28 & -56 & 52 & 6.48 & .001 \\
\hline L Inferior frontal gyrus & 45 & -52 & 32 & 16 & 6.04 & .0001 \\
\hline $\mathrm{R}$ Inferior/middle frontal gyrus & $45 / 46$ & 56 & 24 & 32 & 4.10 & .0001 \\
\hline L Middle temporal gyrus & 21 & -52 & -40 & -4 & 5.37 & .005 \\
\hline Word Exposure Effect $(2 \mathrm{Rw}>1 \mathrm{Rw})$ & \multicolumn{6}{|c|}{ No significant activations } \\
\hline Imageability Effect (Rwc > Rwa) & \multicolumn{6}{|c|}{ No significant activations } \\
\hline Imageability Effect (Rwa > Rwc) & \multicolumn{6}{|c|}{ No significant activations } \\
\hline Interaction & \multicolumn{6}{|c|}{ No significant activations } \\
\hline
\end{tabular}

MNI coordinates and $t$ value for the peak location in a particular identified anatomical cluster $(p<.001,20$ voxels spatial extent) for the statistically significant differences in the corresponding activated regions. Note that only clusters that were significant on a cluster level of $p<.05$ (corrected for multiple comparisons) are listed. $\sim \mathrm{BA}=$ approximate Brodmann's area; $1 \mathrm{Rw}=$ first-sentence real word; $2 \mathrm{Rw}=$ second-sentence real word; Rwa $=$ real-word abstract; Rwc $=$ real-word concrete; $\mathrm{R}=$ right hemisphere; $\mathrm{L}=$ left hemisphere; $\mathrm{SCA}=$ sulcus calcarinus; $p=p$ value for the cluster (corrected for multiple comparisons).

$* p<.0001$. 
Figure 1. Brain areas that were found active in real-word and new-word analysis. (A) Group-average comparisons between first sentence and second sentence for real words (word exposure effect). All the views presented were superimposed on the mean anatomical image formed by averaging all 15 subjects' T1 structural MRI scans mapped into normalized MNI space. $\mathrm{L}=$ left; VWFA = visual word form area. (B) Views in standard stereotactic space of the group-average comparison between second and first sentence for new word (word exposure effect). (C) Average comparisons between new-word concrete and new-word abstract for new-word conditions (imageability effect). (D) Group-average interaction between word exposure and imageability. $\mathrm{L}=$ left; $\mathrm{R}=$ right; $\mathrm{FFG}=$ fusiform gyrus.

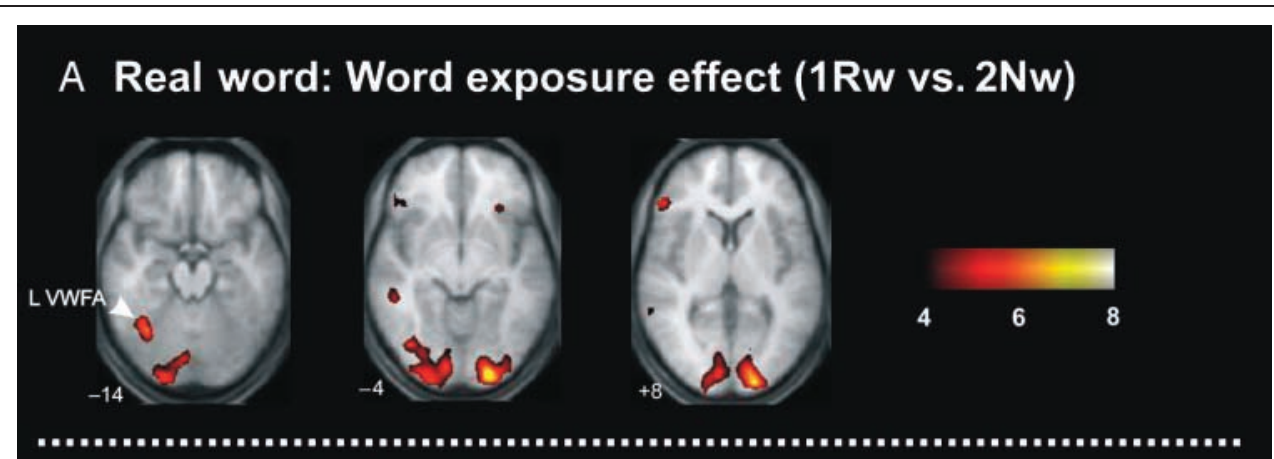

B New word: Word exposure effect (2Rw vs. $1 \mathrm{Nw})$
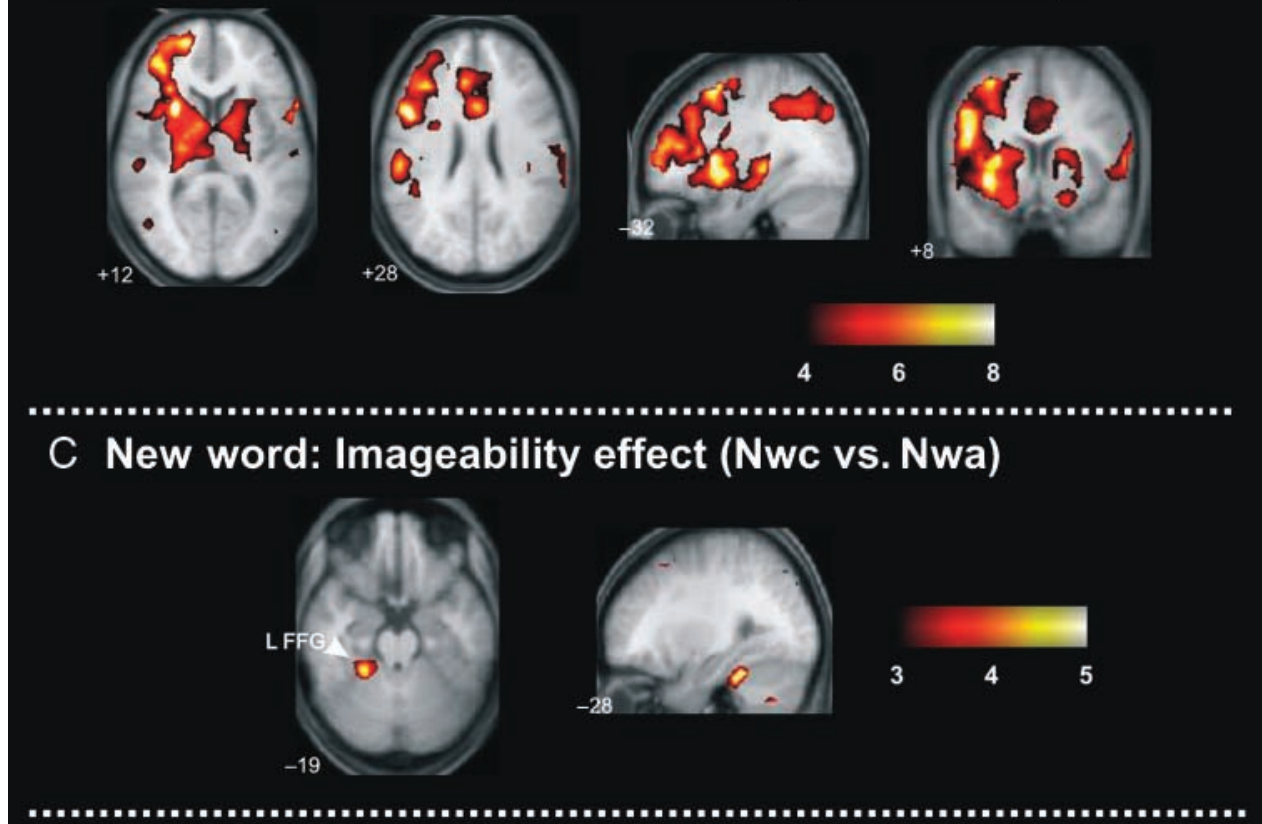

D Interaction
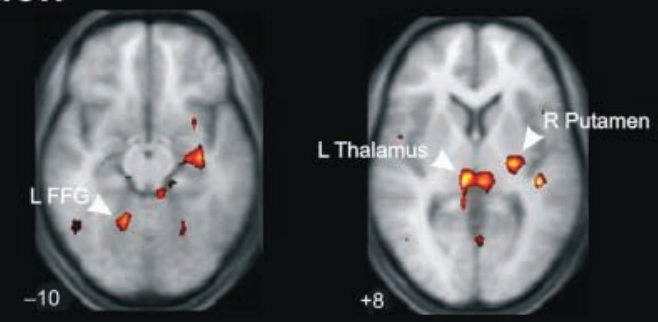

3.5

4.5

4.55 frontal gyrus (BA 46), right anterior cingulate gyrus (BA 32), left middle temporal gyrus (BA 21), right precentral gyrus (BA 4), left inferior parietal lobe (BA 40), right putamen, right caudate body, left IFG (BA 45), left putamen, and left caudate body (Table 2, Figure 1B).

The comparison Nwc versus Nwa (imageability effect) yielded significant activation in the left fusiform gyrus (BA 37) (Figure 1C, Table 2). The opposite contrast did not show any significant activation. Interactions between word exposure and imageability were found in the left thalamus, right putamen, and left fusiform gyrus (BA 20/ 37) (Figure 1D, Table 2). These interactions reflected the increased activation in Nwc for the second sentence (see parameter estimates analysis of these regions in Figure 2B and Figure 3).

\section{New-word vs. Real-word Comparison} (Second Sentence)

The contrast second-sentence real word versus secondsentence new word (word-type effect) revealed anterior and posterior cingulate cortex activation (Table 3). The opposite contrast yielded large activations in various regions of the left hemisphere, including the left IFG (BA 45), 
Table 2. Activation Clusters for Main Effects (Word Exposure and Imageability) and Interaction on New Words

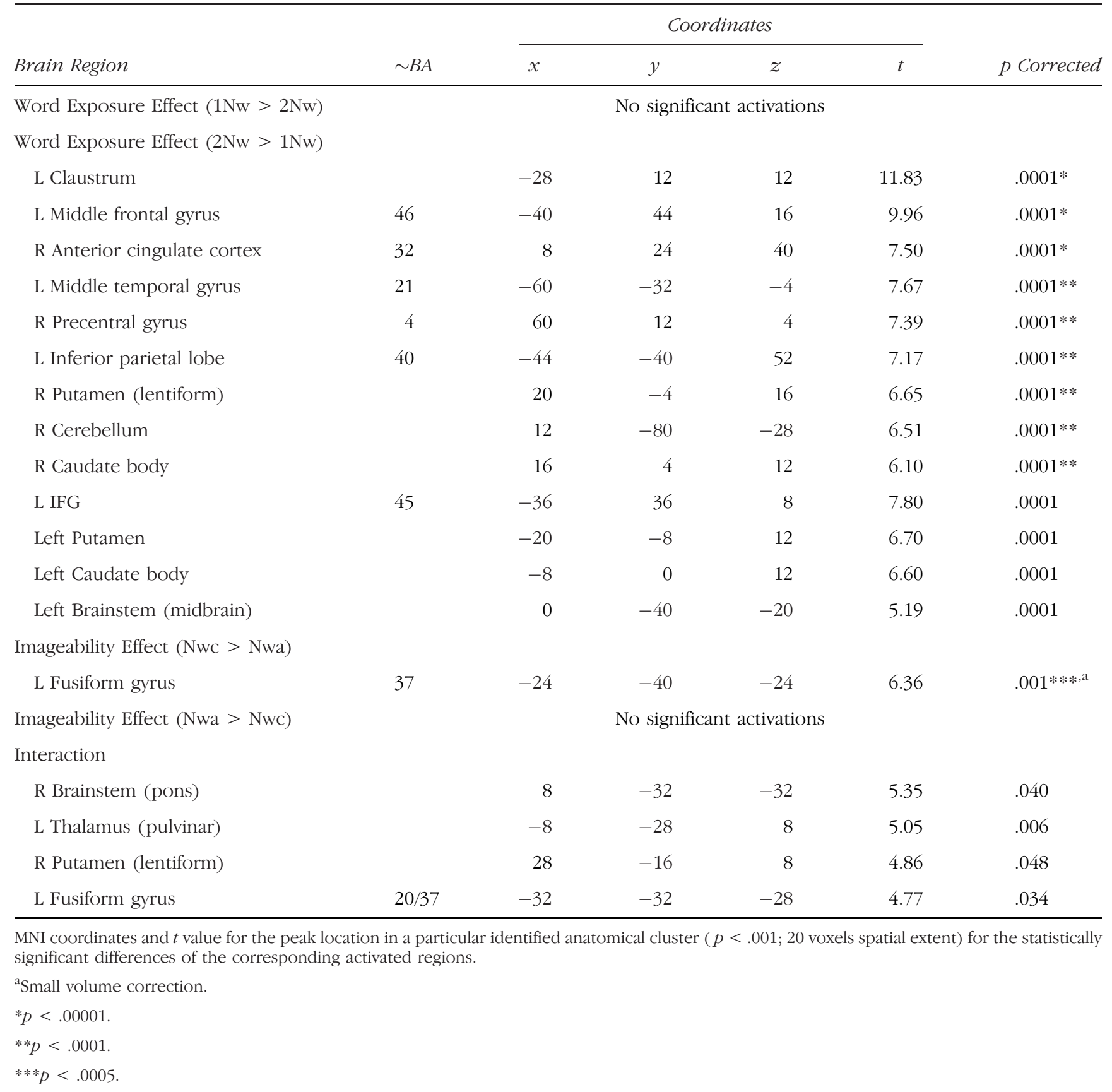

the left middle frontal gyrus (BA 46), fusiform gyrus bilaterally (BA 37, VWFA), anterior cingulate cortex/ presupplementary motor area (ACC/pre-SMA, BA 32/6), left inferior parietal lobe (BA 40), the caudate body bilaterally, the thalamus bilaterally, and the left superior temporal gyrus (BA 22) among other regions (see Table 3, Figure 2A).

The concrete versus abstract contrast (imageability effect) showed activation in the left fusiform gyrus (BA 37) (Figure 2B, Table 3). This region matched with the activation in the fusiform gyrus observed in the previous contrast between Nwc and Nwa (see imageability effect in the previous section). There were no areas displaying significant activation for the opposite contrast. No significant interaction was found between word type and imageability.

\section{Analysis of the Areas Modulated by Word Imageability}

To further pinpoint the effects of imageability, ANOVAs were performed on the parameter estimates at the peak coordinates of the following regions: left fusiform gyrus (including anterior fusiform gyrus and VWFA) and right middle temporal gyrus. The regions were selected because they have been implicated in previous studies (Bedny \& Thompson-Schill, 2006; Fliessbach et al., 2006; 


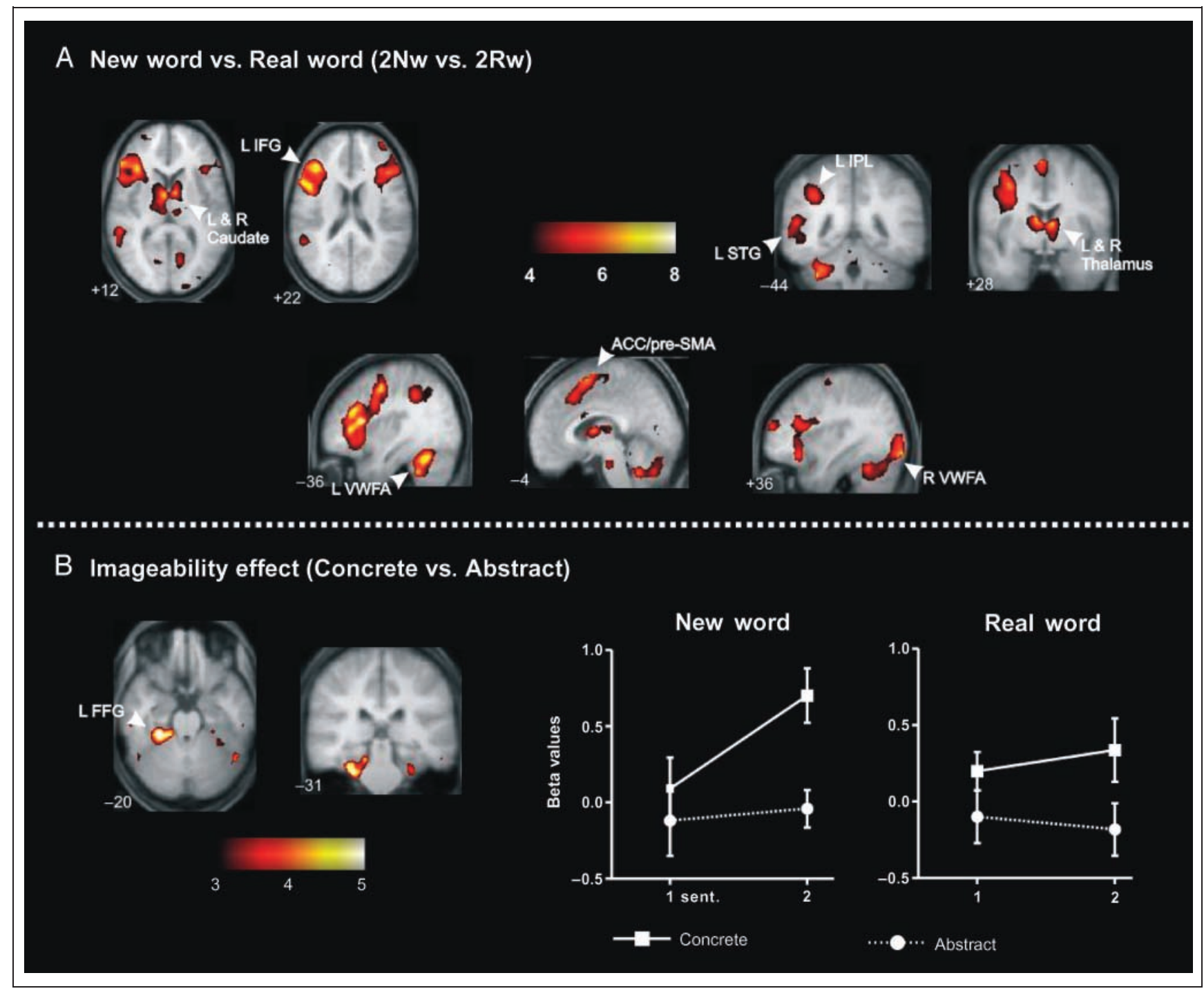

Figure 2. Activation of the anterior ventral fusiform gyrus in learning new concrete words. (A) Group-average comparisons between new word and real word (word-type effect). (B) Group-average comparison between concrete and abstract (imageability effect). Group-average beta values for first and second sentence of new word and real word (abstract-concrete) in the left fusiform gyrus (BA 37, coordinates $-28,-36,-24)$. Error bars indicate standard error of the mean. $\mathrm{L}=$ left; $\mathrm{R}=$ right; IFG = inferior frontal gyrus; IPL = inferior parietal lobe; STG = superior temporal gyrus; VWFA = visual word form area; ACC/pre-SMA = anterior cingulate cortex/pre-supplementary motor area; FFG = fusiform gyrus; sent. $=$ sentence.

Sabsevitz et al., 2005; Wallentin et al., 2005; Giesbrecht et al., 2004; Whatmough et al., 2004; Noppeney \& Price, 2002). The results of the ANOVA analysis are summarized in Table 4.

For the anterior left fusiform gyrus (BA 37) (Figure 2B, Table 3), concrete stimuli evoked greater activation than abstract stimuli. Interestingly, concrete stimuli were associated with greater activation than abstract stimuli in both the first and second sentences. Moreover, during the second sentence, Nwc showed greater activation than Rwc $[t(14)=2.31, p<.036]$. A more posterior portion of the fusiform gyrus, corresponding to the VWFA (see Figures 1A, 2A, and 3), showed a different pattern: Nwc showed an increase in activation from the first to second sentence, whereas Nwa showed no differences.
For real words, a deactivation was seen for the second sentence. The same pattern of activation was observed on the right VWFA. Thus, the ventral anterior fusiform gyrus was modulated by imageability in general, whereas the VWFA showed modulation only for new words.

The right middle temporal gyrus (BA 21) showed effects of imageability for real words. We observed that this region showed greater activation for 1Rwa compared to 1Rwc (see Table 4 and Figure 3). Although newword conditions did not show imageability effects in this region, Rwa showed a greater level of activity than Rwc during both the first and second sentences. Both realword conditions were associated with a decrease in activation during the second sentence compared to the first sentence. 
In sum, the ventral anterior fusiform gyrus showed greater activation for concrete items, with the largest activation pattern being observed for the new-word concrete condition. Interestingly, the VWFA showed imageability modulation only for new-word conditions (greater activity for the Nwc condition). In contrast to the concreteness effects observed in the fusiform gyrus, the right middle temporal gyrus showed the reverse pattern. Abstract items were associated with greater levels of activation, but this effect was observed only for the real-word conditions.

\section{DISCUSSION}

This experiment used fMRI to study the association of new words to an existing meaning derived from sentential context. In particular, it was asked how this process differs depending on a word's concreteness. The main finding of the present study is that the left fusiform gyrus plays a differential role depending on a word's imageability. This region was only involved in learning new concrete words while practically no activation was observed for new abstract words. Whereas no region showed differential involvement in learning the meaning of abstract new words, the right middle temporal gyrus (BA 21) was more activated for real abstract words. We will further discuss the learning effects (behaviorally) obtained, the involvement of the fusiform and the middle temporal gyrus in learning concrete and abstract new words and, finally, the implication of other regions activated during the learning task.

\section{Word Learning Behavioral Effects}

The correct meaning assignment task conducted after each experimental run indicated that both concrete and abstract words were successfully learned from contextual information (Chaffin, Morris, \& Seely, 2001). The mean percentage of correct meaning assignment obtained was $68 \%$, very similar to our previous results using only concrete words (Mestres-Missé, Camara, Rodriguez-Fornells, Rotte, \& Munte, 2008). Although both types of new words were successfully learned, concrete words were associated with faster RTs and fewer omissions than abstract words. The present results replicate previous findings showing that concrete words are easier to learn and to remember than abstract words in second-language learning (de Groot, 2006; de Groot \& Keijzer, 2000; van Hell \& Candia-Mahn, 1997). Effects of word concreteness have not only been found in novice learners of a second language but also in fluent bilinguals who translated concrete words more quickly and accurately than abstract

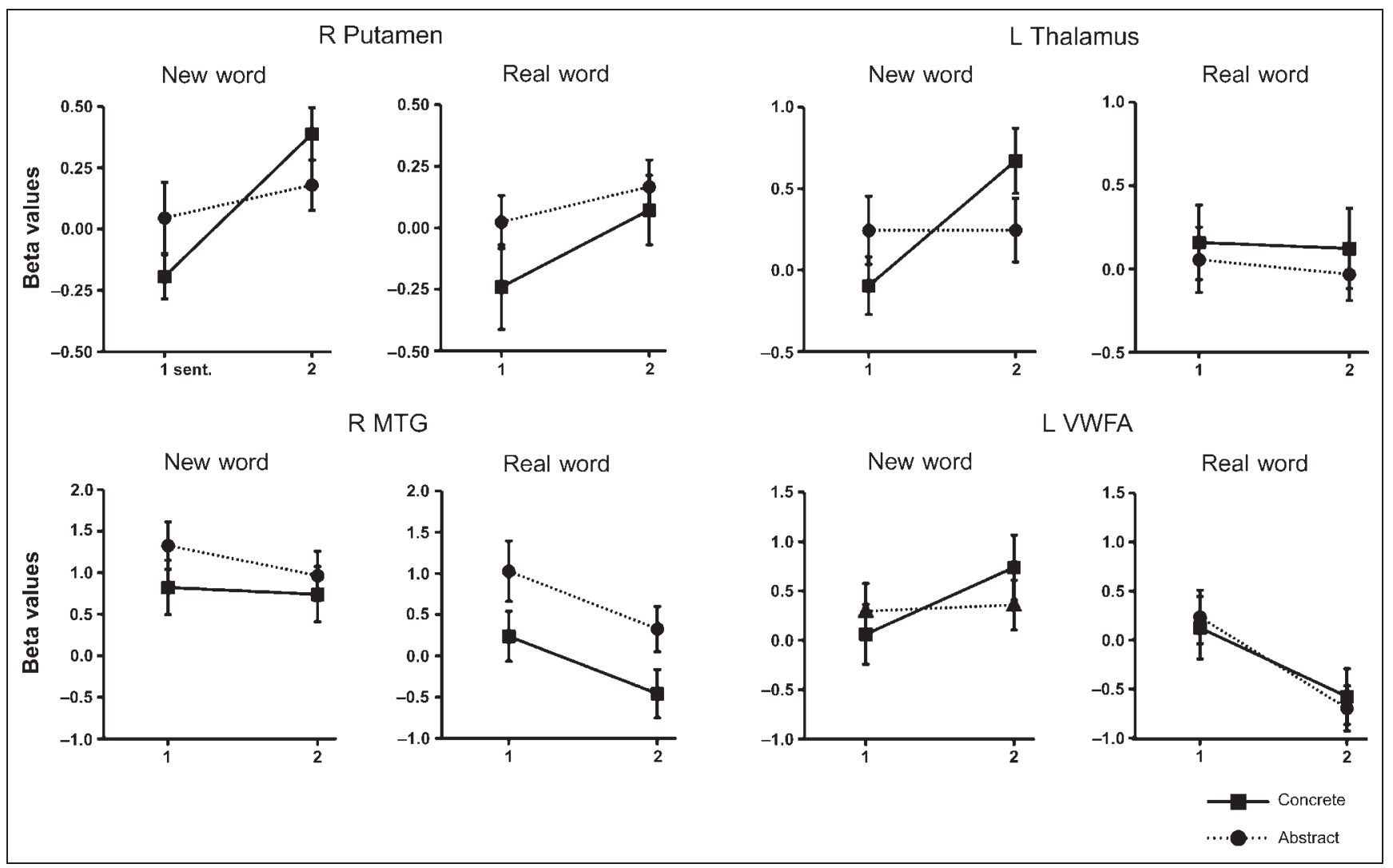

Figure 3. Parameter estimates analysis for concrete and abstract new words and real words. Group-average beta values for first and second sentence of new-word and real-word condition (abstract-concrete) in the right putamen (coordinates $28,-16,8)$, left thalamus $(-8,-28,8)$, right middle temporal gyrus $(52,-24,-8)$, and left VWFA $(-36,-56,-20)$. Error bars indicate standard error of the mean. sent. $=$ sentence. 
Table 3. Activation Cluster for Main Effects Word Type (Real Word vs. New Word) and Imageability (Concrete vs. Abstract) and Interaction between These Factors on the Second Sentence

\begin{tabular}{|c|c|c|c|c|c|c|}
\hline \multirow[b]{2}{*}{ Brain Region } & \multirow[b]{2}{*}{$\sim B A$} & \multicolumn{4}{|c|}{ Coordinates } & \multirow[b]{2}{*}{$p$ Corrected } \\
\hline & & $x$ & $y$ & $z$ & $t$ & \\
\hline \multicolumn{7}{|l|}{ Word Type Effect $(2 \mathrm{Rw}>2 \mathrm{Nw})$} \\
\hline Anterior cingulate cortex & 32 & 0 & 28 & -8 & 7.84 & .0001 \\
\hline L Posterior cingulate gyrus & 31 & -4 & -52 & 32 & 4.88 & .017 \\
\hline \multicolumn{7}{|l|}{ Word Type Effect $(2 \mathrm{Nw}>2 \mathrm{Rw})$} \\
\hline L Insula/IFG & 13 & -36 & 20 & 16 & 9.15 & $.0001^{*}$ \\
\hline L IFG & 45 & -36 & 32 & 8 & 8.19 & $.0001^{*}$ \\
\hline L IFG & 44 & -48 & 8 & 24 & 8.09 & $.0001^{*}$ \\
\hline L Fusiform gyrus & 37 & -36 & -56 & -20 & 7.58 & $.0001 * *$ \\
\hline R Middle occipital gyrus & 18 & 40 & -88 & -8 & 7.25 & $.0001 * *$ \\
\hline L Middle frontal gyrus & 46 & -36 & -4 & 48 & 7.19 & $.0001 * *$ \\
\hline R Fusiform gyrus & 37 & 32 & -52 & -24 & 6.81 & $.0001^{* *}$ \\
\hline R Inferior frontal gyrus & 45 & 44 & 24 & 20 & 6.83 & $.0001^{* *}$ \\
\hline L Anterior cingulate cortex/pre-SMA & $32 / 6$ & -4 & 4 & 64 & 6.55 & $.0001^{* *}$ \\
\hline L Caudate body & & -8 & -4 & 16 & 7.40 & .0001 \\
\hline R Caudate body & & 8 & 0 & 12 & 7.33 & .0001 \\
\hline L Superior temporal gyrus & 22 & -60 & -52 & 16 & 6.72 & .0001 \\
\hline L Cuneus & 18 & -24 & -96 & -8 & 5.83 & .003 \\
\hline L Inferior parietal lobe & 40 & -40 & -44 & 44 & 5.77 & .0001 \\
\hline L Brainstem (pons) & & -4 & -20 & -24 & 5.27 & .035 \\
\hline R Thalamus (medial dorsal) & & 8 & -20 & 12 & 4.92 & .0001 \\
\hline L thalamus & & -8 & -20 & 16 & 4.88 & .0001 \\
\hline R Middle frontal gyrus & 6 & 32 & -8 & 68 & 4.73 & .030 \\
\hline R Thalamus & & 20 & -16 & 16 & 4.72 & .0001 \\
\hline L Cuneus (SCA) & 17 & -12 & -76 & 4 & 4.38 & .019 \\
\hline \multicolumn{7}{|l|}{ Imageability Effect $(C>A)$} \\
\hline L Fusiform gyrus & 37 & -28 & -36 & -24 & 5.74 & .002 \\
\hline Imageability Effect $(\mathrm{A}>\mathrm{C})$ & \multicolumn{6}{|c|}{ No significant activations } \\
\hline Interaction & \multicolumn{6}{|c|}{ No significant activations } \\
\hline
\end{tabular}

MNI coordinates and $t$ value for the peak location in a particular identified anatomical cluster $(p<.001 ; 20$ voxels spatial extent) for the statistically significant differences of the corresponding activated regions. $\mathrm{A}=$ abstract; $\mathrm{C}=$ concrete.

$* p<.00001$.

$* * p<.0001$.

words (van Hell \& de Groot, 1998a, 1998b; de Groot \& Poot, 1997).

Interestingly, in the new-word recognition test carried out after the scanning session, approximately 31\% of the new words were correctly recognized with no differences between concrete and abstract words. When recalling the meaning of the recognized words, concrete meanings were better recalled than abstract meanings albeit the small percentage of new-word meanings that were recalled. It is important to bear in mind that the focus of the present vocabulary learning simulation is on the process of inferring the meaning of a new word from a verbal context (Frantzen, 2003; Nation, 2001; Nagy \& Gentner, 1990; Nagy, Anderson, \& Herman, 1987). Therefore, the 
Table 4. Parameter Estimates Analysis

\begin{tabular}{|c|c|c|c|c|c|c|c|}
\hline & \multirow[b]{2}{*}{ Peak Coordinates } & \multicolumn{3}{|c|}{ New Word } & \multicolumn{3}{|c|}{ Real Word } \\
\hline & & $W E$ & $I$ & $W E \times I$ & $W E$ & $I$ & $W E \times I$ \\
\hline $\mathrm{L}$ aFFG & $-28,-36,-24$ & $5.2 *$ & $28.04 * * *$ & $10.02 * * *$ & $n s$ & $12.8^{* * *}$ & $n s$ \\
\hline L VWFA & $-36,-56,-20$ & $n s$ & $n s$ & $13.03 * *$ & $54.05 * * *$ & $n s$ & $n s$ \\
\hline R MTG & $52,-24,-8$ & ns & ns & ns & $10.3 * *$ & $19.4^{* * *}$ & ns \\
\hline \multicolumn{8}{|c|}{$\begin{array}{l}\text { Pairwise ANOVAs restricted to new word and real word, respectively, comparing the different conditions and regions of interest. WE }=\text { word } \\
\text { exposure (first vs. second sentence); } \mathrm{I}=\text { imageability; } \mathrm{L} \text { aFFG }=\text { left anterior fusiform gyrus; } \mathrm{L} \text { VWFA }=\text { left visual word form area; } \mathrm{R} \text { MTG }=\text { right } \\
\text { middle temporal gyrus; } n s=\text { nonsignificant. Degrees of freedom }=1,14 . \\
* p<.05\end{array}$} \\
\hline
\end{tabular}

correct meaning assignment task used within the scanning runs and the new-word recognition task used at the end of the fMRI session should only be considered indirect indexes of the meaning discovery process. In previous studies using similar materials and the same paradigm, the percentage of correct meaning extraction was approximately 91\% when directly evaluated after the presentation of the verbal context (Mestres-Missé et al., 2007). The lack of correct recall of the meanings at the end of the experiment can easily be explained by taking into account that participants had to remember the meaning of 80 new words in roughly $1 \mathrm{hr}$ and $15 \mathrm{~min}$, each presented only in one trial without repetitions. Further training would likely lead to a gradual increase of recalled meanings. It is also important to stress that the memory tests we used were focused on the evaluation of the association between the new word and an already existing concept. Other psycholinguistic tasks (e.g., semantic priming, lexical decision, naming tasks, picture-word interference) would be needed as well as longitudinal designs in order to evaluate how the new words are integrated in the mental lexicon. Whereas several studies have investigated how new words are integrated in the lexicon in this way, they do not provide information as to the neural networks involved (Tamminen \& Gaskell, 2008; Clay, Bowers, Davis, \& Hanley, 2007; Dumay \& Gaskell, 2007; Gaskell \& Dumay, 2003).

\section{Imageability Effects in the Fusiform and Middle Temporal Gyrus}

Several regions were modulated by word imageability. The activation found in the ventral anterior fusiform gyrus for concrete items in the present study is consistent with earlier studies (Bedny \& Thompson-Schill, 2006; Fliessbach et al., 2006; Sabsevitz et al., 2005; Wallentin et al., 2005; Giesbrecht et al., 2004; Whatmough et al., 2004; Wise et al., 2000; Mellet et al., 1998; D'Esposito et al., 1997; Fletcher et al., 1995). This part of the fusiform gyrus is a region of the inferotemporal cortex associ- ated with high-level visual processing (Ishai, Ungerleider, \& Haxby, 2000; Chao, Haxby, \& Martin, 1999; Mellet et al., 1998; D'Esposito et al., 1997). Activation of this region has been reported in studies of word reading (Cohen et al., 2002; Dehaene, Le, Poline, Le, \& Cohen, 2002; Buchel, Price, \& Friston, 1998), object categorization (Gerlach et al., 2002; Gerlach, Law, Gade, \& Paulson, 2000; Martin et al., 2000; Gerlach, Law, Gade, \& Paulson, 1999; Martin, Wiggs, Ungerleider, \& Haxby, 1996), semantic association (Vandenberghe, Price, Wise, Josephs, \& Frackowiak, 1996), object naming (Damasio, Grabowski, Tranel, Hichwa, \& Damasio, 1996; Martin et al., 1996; Price, Wise, \& Frackowiak, 1996), encoding of pictures (Stern et al., 1996) and words (Wagner et al., 1998), and word concreteness (Bedny \& Thompson-Schill, 2006; Sabsevitz et al., 2005; Wallentin et al., 2005; Fiebach \& Friederici, 2004; Mellet et al., 1998; D'Esposito et al., 1997; Fletcher et al., 1995). The left ventral anterior fusiform gyrus has also been recruited in context verification tasks where participants had to link the meaning of a target word with the meaning of a preceding sentential context (Hoenig \& Scheef, 2005; Ryan et al., 2001). Moreover, neuropsychological studies of patients with lesions in the inferior temporal cortex tend to show a selective preservation of abstract compared to concrete concepts (Marshall et al., 1996; Breedin et al., 1994; Warrington \& Shallice, 1984; Warrington, 1975, 1981).

Our results extend these previous findings by showing that this region is involved in learning the meaning associated to concrete new words. Indeed, prior research has shown that retrieving information about object attributes engages the same areas that mediate their perceptual processing, suggesting the existence of distributed semantic representations (Martin, 2001; Martin et al., 2000; Barsalou, 1999; Kosslyn et al., 1999; Damasio, 1989; Allport, 1985). Crutch and Warrington (2005) have recently proposed that representations of concrete words can be thought of in terms of a well-organized hierarchical structure (categorical organization), whereas abstract words have a shallower (associative) organization. 
This categorical organization of superordinate and subordinate representations for concrete words allows the sharing of features with overlapping concepts, which might have allowed the participants to easily infer the meaning of the concrete new words. This might explain the greater activation of the anterior ventral fusiform gyrus in Nwc compared to Rwc. In the search for the matching concept, several candidates associated to the underlying hidden concept might be activated. If only the conceptual representation of the hidden (target) word had been activated in the Nwc condition, a difference between real and new-word conditions should not have been obtained (see Figure 2B). This is in line with previous suggestions that this region is involved in conceptual and/or lexical processing and not only related to stimulus feature processing (Martin, 2007; Simons, Koutstaal, Prince, Wagner, \& Schacter, 2003; Koutstaal et al., 2001).

The selective activation of the ventral anterior fusiform gyrus for concrete words and new-word learning in the present study is consistent with one of the most important predictions of the dual-coding theory (Paivio, 2006). The activation of the nonverbal imagery symbolic system in concrete words predicts the activation of several areas of the ventral visual or "object properties processing" pathway, as it was the case in the present study. Previous studies also support the involvement of these regions in visual imagery (see meta-analysis in Thompson \& Kosslyn, 2000). In contrast, the context availability theory (Schwanenflugel \& Shoben, 1983) proposes the activation of a single-amodal system, represented by a general neural network or region, which could be only modulated due to the differential contextual availability in concrete and abstract words. As virtually no activation of the ventral anterior fusiform gyrus was seen for abstract words, the present results do not support this model. Importantly, we presented the words and new words in very supportive sentence contexts which, if anything, should have mitigated any concreteness effects according to the contextual availability theory.

As the conceptual representations associated to abstract words are more disperse and branched in semantic memory due to their associative structure (Crutch \& Warrington, 2005; Schwanenflugel \& Shoben, 1983), one should expect abstract words to activate regions involved in deeper semantic processing. Indeed, our results showed middle temporal gyrus involvement in the processing of abstract real words (see also Pexman et al., 2007), but no differential activation was found for the learning of abstract new words compared to concrete new words. However, the activation in the middle temporal gyrus might be confounded with the task of meaning extraction, as both new-word conditions have high semantic processing demands (see also MestresMissé et al., 2008). A further explanation for the lack of activations specifically reflecting the association of abstract new words to their meaning might be that this process is spatially more dispersed with a greater interitem variability. This explanation would agree with the idea that the meanings of abstract words tend to be more variable and less redundant across contexts, frequently having related but distinct meanings.

We also found that a more posterior and dorsal region of the fusiform gyrus, known as the VWFA, showed a stronger response to the concrete new-word condition (Nwc) especially during the second sentence. The VWFA has been related to prelexical representation of visual words, responding preferentially to letter strings than to other categories of visual stimuli (for a review, see Cohen \& Dehaene, 2004), and to word and word-like (pseudowords) stimuli than consonant strings (Binder, Medler, Westbury, Liebenthal, \& Buchanan, 2006; Cohen et al., 2002; Dehaene et al., 2002; Buchel et al., 1998). However, other studies have found larger activation in this region for pseudowords compared to words which challenges the view of the VWFA as limited to prelexical processing (Abutalebi et al., 2007; Kronbichler et al., 2004; Mechelli, Gorno-Tempini, \& Price, 2003). The VWFA has been reported to show no differences in activation as a function of semantic category (Dehaene et al., 2002) or of word imageability (Buchel et al., 1998). Recently, Abutalebi et al. (2007) found larger activation in this region in a task where participants had to link known semantic and phonological information to a new orthographic word form. Therefore, the larger activation found in this study for new words might be attributed to the retention and storage of visual word forms. At present, and considering the previous literature, we do not have a clear explanation about the increased activation seen in this region when learning concrete new word forms. Further research might be needed in order to understand the differences in activation found between concrete and abstract new words and the role of this region in word learning.

\section{Other Brain Regions Involved in Word Learning}

A distributed brain network was involved in word learning that includes the left IFG (BA 45), middle and superior temporal gyrus (BA 21/22), ACC/pre-SMA (BA 32/6), and several subcortical areas. This network corroborated the pattern observed in an earlier study (Mestres-Missé et al., 2008).

In relation to the basal ganglia, it has been shown that these regions play an important role in human learning (Seger, 2006; Seger \& Cincotta, 2006). These structures are part of several parallel loops involving distinct regions of prefrontal and, to a lesser extent, temporal and parietal cortex (Middleton \& Strick, 2000). Prefrontal cortex and the striatum are often simultaneously active during learning (Seger \& Cincotta, 2006). The thalamus has been shown to be involved in object recall and lexical retrieval (Crosson et al., 2003; Kraut et al., 2002; Crosson et al., 1999). 
Figure 4. New-word abstract induced greater activation than new-word concrete during the first sentence in ACC/pre-SMA. Group-average beta values for first and second sentence of new-word and real-word condition (abstract-concrete) in left ACC/pre-SMA (-4, 4, 64). Error bars indicate standard error of the mean. sent. $=$ sentence.

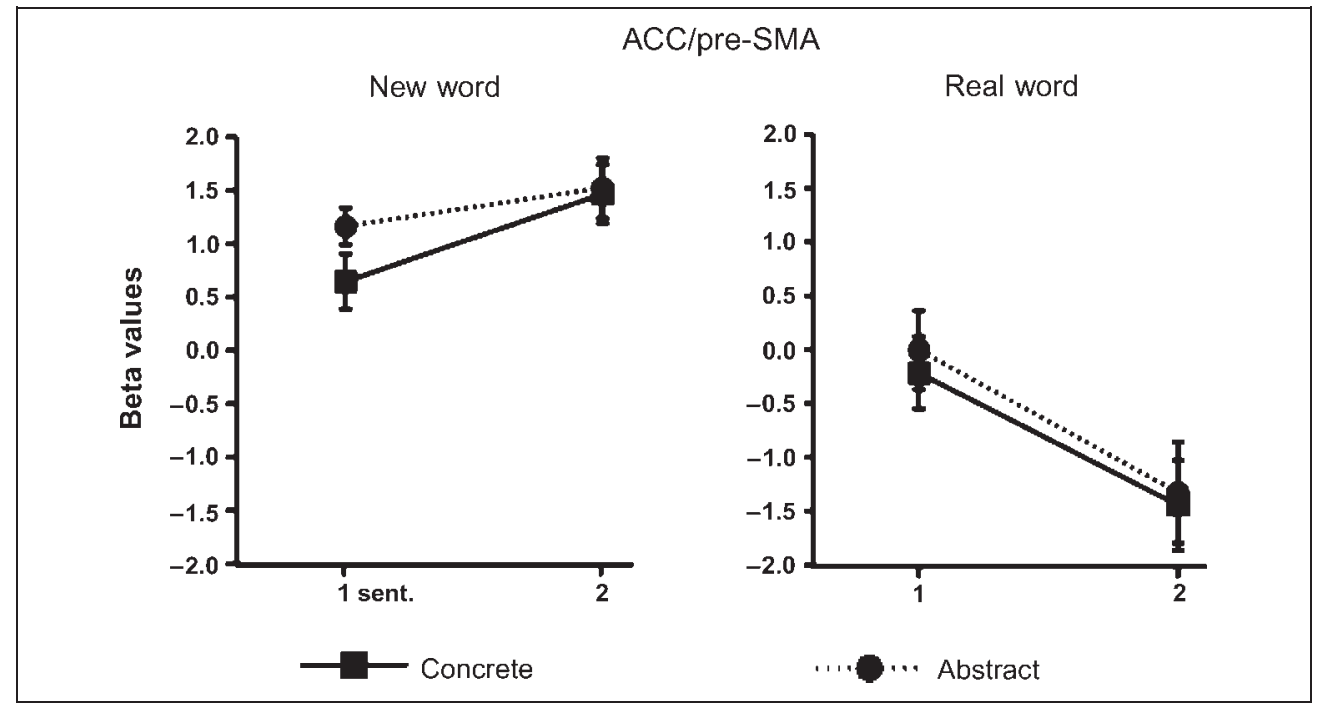

In our previous study (Mestres-Missé et al., 2008), we hypothesized that the coupling between ACC and subcortical structures might be involved in facilitating the retrieval of lexical items from preexisting stores during language generation. The basal ganglia might induce and maintain a processing bias toward the selection of a candidate meaning. Once an appropriate lexical item has been selected, the bias may be overridden allowing further processing of the selected item by frontal structures (Crosson et al., 2003), and later storage in medialtemporal regions. Similarly, Ullman (2006) has proposed the existence of a frontal-subcortical circuit involving the anterior IFG (pars triangularis, BA 45) and basal ganglia, which might subserve the retrieval of lexical/semantic knowledge.

One important finding is that we observed greater activation during the association of concrete but not abstract new words to their meaning in some regions of this loop (the basal ganglia, thalamus, and ACC/preSMA). Importantly, these regions are not directly linked to high-level visual processing (i.e., the imageability aspect of concrete words). Nwa induced greater activation than Nwc during the first sentence in ACC/pre-SMA $[t(14)=$ $-2.2, p<.038$; see Figure 4$]$. The basal ganglia and the thalamus showed the pattern of greater activation for new-word conditions compared to real-word ones during the second sentence (Figure 2A, Table 3). In contrast, in the left thalamus and right putamen, only Nwc was associated with an increase on activation in the second sentence when compared to Nwa (see Figure 3). We propose that the greater activation for concrete new words reflects faster and easier selection of a candidate meaning, allowing greater activity to accrue in this network. This activation can thus be viewed as the neural counterpart of the behavioral finding that concrete words are learned easier, faster, and better than abstract words (de Groot, 2006; de Groot \& Keijzer, 2000; van Hell \& CandiaMahn, 1997).
Finally, learning of new words also led to activation of inferior parietal cortex, which has previously been shown to reflect learning of new words through association (Breitenstein et al., 2005), learning new labels for new tools (Cornelissen et al., 2004), second-language proficiency (Mechelli et al., 2004), and recently, the size of the vocabulary in adolescents (Lee et al., 2007). Further studies are required to understand the exact function of this region in word learning.

\section{Conclusions}

To summarize, the present study showed the differential involvement of some regions in the meaning assignment to new concrete and abstract words. The most important finding is that the ventral anterior fusiform gyrus is exclusively engaged in the association of new concrete words to their meaning. This provides further evidence for the existence of qualitative differences in learning, storing, and processing concrete and abstract words.

\section{APPENDIX A: NOVEL CONCRETE WORDS-CORRESPONDING SPANISH WORDS (ENGLISH TRANSLATION)}

Adarato-coche (car); alacro-cigarro (cigarette); areosol (sun); atelo-queso (cheese); bilsa-iglesia (church); bisaco-aceite (oil); bisno-colegio (school); brande-llave (key); bupido-suelo (floor); capino-cine (movie theater); cartuno-zapato (shoe); catebia-escalera (stair/ ladder); centiño-barco (boat/ship); cerino-papel (paper); cija-uña (nail); cilso-cuadro (painting); clita-bandera (flag); conua-guitarra (guitar); coparo-médico (doctor); curteno-otoño (fall); desuba-isla (island); diero-bar (bar); difo-pan (bread); duta-boca (mouth); enrate-café (coffee); faleto-calendario (calendar); fato-diente (tooth); fiamba-estrella (star); flesta-película (movie); foba-nube 
(cloud); fostico-amigo (friend); gepo-plato (plate); geriasangre (blood); herno-teléfono (telephone); ilero-mar (see); imgeo-león (lion); insata-vela (candle); lerticopez (fish); lianto-corazón (heart); libeso-aeropuerto (airport); lineto-sombrero (hat); mabrona-naranja (orange); madida-nariz (nose); masuo-espejo (mirror); matreñobotón (button); mesato-azúcar (sugar); miloma-ventana (window); minto-periódico (newspaper); motra-cocina (kitchen); nalosa-gota (drop); nilecas-gafas (glasses); ilopo-cuchillo (knife); obeto-árbol (tree); ofa-mosca (fly); omblón-pantalón (trousers); onito-brazo (arm); oprisa-tarjeta (card); paceto-anillo (ring); pecua-mancha (stain); pieto-paraguas (umbrella); pilso-gato (cat); pisalfútbol (soccer); pruba-leche (milk); pune-ojo (eye); ralidacama (bed); rasiño-hotel (hotel); recea-canción (song); restate-ordenador (computer); rotiro-fuego (fire); seomorío (river); sibrano-televisor (television); sionte-oído (ear); tarra-mesa (table); tilapo-ascensor (elevator); trepto-cinturón (belt); tulso-casco (helmet); valo-mapa (map); varosa-silla (chair); vatesa-ciudad (city); viato-dedo (finger).

\section{APPENDIX B: NOVEL ABSTRACT WORDS-CORRESPONDING SPANISH WORD (ENGLISH TRANSLATION)}

Adrema-solución (solution); ango-principio (beginning); astino-plan (plan); asiro-milagro (miracle); atual-titular (holder); belinca-cultura (culture); belto-volumen (volume); beste-turno (turn); biteco-tamaño (size); bofín-rastro (trace); camira-noticia (a piece of news); canduta-teoría (theory); casel-acuerdo (agreement); cipita-importancia (importance); crosna-denuncia (report/complaint); cuchenoefecto (effect); cunto-ejemplo (example); denería-venganza (revenge); desala-prueba (proof); dicamo-significado (meaning); ditena-curiosidad (curiosity); emsa-imaginación (imagination); espel-pecado (sin); espimo-fracaso (failure); esruba-presión (pressure); etudo-destino (fate); fimetaduda (doubt); findo-motivo (reason); flata-edad (age); gaena-seguridad (security); gamila-suerte (luck); gasbadescripción (description); graenta-generación (generation); guna-reserva (reservation); gurato-tratamiento (treatment); hareta-oportunidad (opportunity); idona-influencia (influence); imbra-broma (joke); infaco-control (control); isama-inteligencia (intelligence); lapio-eco (echo); lecocurso (course); macito-misterio (mistery); mampo-límite (limit); midoga-diferencia (difference); milso-secreto (secret); motefa-fe (faith); nacal-mito (myth); niepa-tradición (tradition); nilata-adopción (adoption); nosa-talla (size); oceta-experiencia (experience); oleto-final (final/ending); olusna-información (information); oviro-cuidado (care); pesmola-norma (rule); piloma-intención (intention); pinocasganas (to feel like doing something); puca-pausa (pause); pusofa-conclusión (conclusion); queseja-crítica (criticism); rasinta-dificultad (difficulty); recerdo-valor (value); recolaposición (position); refia-decisión (decision); remocapersonalidad (personality); rinaca-vergüenza (shame); ristro-perdón (forgiveness); rolantre-paro (unemployment); sileca-combinación (combination); silopa-espera (wait); silta-ayuda (help); sito-resultado (result); tacela-duración (duration); teba-energía (energy); tería-culpa (fault); tesca-conciencia (conscience); tezo-error (mistake); tromo-reto (challenge); ulina-justicia (justice).

\section{Acknowledgments}

This work was supported by grants from the Spanish Government (Ramon y Cajal, SEJ2005-06067/PSIC), Generalitat de Catalunya (SGR2005-00831) to A. R. F. and a predoctoral grant to A. M. M. and from the DFG to T. F. M. The work was conducted at the Magdeburg Center for Advanced Imaging supported by a BMBF center grant (contract 01GO0202). We thank T. Cunillera and E. Camara for their help in testing the materials and data analysis, and P. Indefrey, B. Jansma, M. Laine, and $\mathrm{P}$. Ramos for their comments on the present work.

Reprint requests should be sent to Anna Mestres-Missé, Department of Neuropsychology, University of Magdeburg, Universitätsplatz, 2 (Geb. 24), 39106 Magdeburg, Germany, or via e-mail: amestres@ub.edu.

\section{Note}

1. In the present study, "concrete and abstract word or new word forms" are used in order to refer to the word or new word forms (existing or new lexemes) that symbolize concrete or abstract conceptual information, respectively. The terms "abstract" and "concrete word forms" have been used systematically in the literature (Paivio, 2006; Crutch \& Warrington, 2005; Kroll \& Merves, 1986; Schwanenflugel \& Shoben, 1983) even though this distinction is only applicable to the knowledge or conceptual representations a word refers to.

\section{REFERENCES}

Abutalebi, J., Keim, R., Brambati, S. M., Tettamanti, M., Cappa, S. F., De, B. R., et al. (2007). Late acquisition of literacy in a native language. Human Brain Mapping, 28, 19-33.

Allport, D. A. (1985). Distributed memory, modular subsystems and dysphasia. In S. K. Newman \& R. Epstein (Eds.), Current perspectives in dysphasia (pp. 32-60). Edinburgh:

Churchill Livingstone.

Ashburner, J., \& Friston, K. J. (1999). Nonlinear spatial normalization using basis functions. Human Brain Mapping, 7, 254-266.

Barsalou, L. W. (1982). Context-independent and context-dependent information in concepts. Memory $\mathcal{E}$ Cognition, 10, 82-93.

Barsalou, L. W. (1999). Perceptual symbol systems. Behavioral and Brain Sciences, 22, 577-609.

Bedny, M., \& Thompson-Schill, S. L. (2006). Neuroanatomically separable effects of imageability and grammatical class during single-word comprehension. Brain and Language, 98, 127-139.

Binder, J. R., Medler, D. A., Westbury, C. F., Liebenthal, E., \& Buchanan, L. (2006). Tuning of the human left fusiform gyrus to sublexical orthographic structure. Neuroimage, 33, 739-748.

Binder, J. R., Westbury, C. F., McKiernan, K. A., Possing, E. T., \& Medler, D. A. (2005). Distinct brain systems for processing concrete and abstract concepts. Journal of Cognitive Neuroscience, 17, 905-917. 
Bloom, P. (2000). How children learn the meanings of words. Cambridge, MA: MIT Press.

Breedin, S. D., Saffran, E. M., \& Coslett, H. B. (1994). Reversal of the concreteness effect in a patient with semantic dementia. Cognitive Neuropsychology, 11, 617-660.

Breitenstein, C., Jansen, A., Deppe, M., Foerster, A. F., Sommer, J., Wolbers, T., et al. (2005). Hippocampus activity differentiates good from poor learners of a novel lexicon. Neuroimage, 25, 958-968.

Buchel, C., Price, C., \& Friston, K. (1998). A multimodal language region in the ventral visual pathway. Nature, 394, 274-277.

Chaffin, R., Morris, R. K., \& Seely, R. E. (2001). Learning new word meanings from context: A study of eye movements. Journal of Experimental Psychology: Learning, Memory, and Cognition, 27, 225-235.

Chao, L. L., Haxby, J. V., \& Martin, A. (1999). Attribute-based neural substrates in temporal cortex for perceiving and knowing about objects. Nature Neuroscience, 2, 913-919.

Clay, F., Bowers, J. S., Davis, C. J., \& Hanley, D. A. (2007). Teaching adults new words: The role of practice and consolidation. Journal of Experimental Psychology: Learning, Memory, and Cognition, 33, 970-976.

Cocosco, C. A., Kollokian, V., Kwan, R. K. S., \& Evans, A. C. (1997). Online interface to a 3-D MRI simulated brain database. Neuroimage, 5, S425.

Cohen, L., \& Dehaene, S. (2004). Specialization within the ventral stream: The case for the visual word form area. Neuroimage, 22, 466-476.

Cohen, L., Lehericy, S., Chochon, F., Lemer, C., Rivaud, S., \& Dehaene, S. (2002). Language-specific tuning of visual cortex? Functional properties of the visual word form area. Brain, 125, 1054-1069.

Coltheart, M., Patterson, K., \& Marshall, J. (1980). Deep dyslexia. London: Routledge and Kegan Paul.

Cornelissen, K., Laine, M., Renvall, K., Saarinen, T., Martin, N., \& Salmelin, R. (2004). Learning new names for new objects: Cortical effects as measured by magnetoencephalography. Brain and Language, 89, 617-622.

Crosson, B., Benefield, H., Cato, M. A., Sadek, J. R., Moore, A. B., Wierenga, C. E., et al. (2003). Left and right basal ganglia and frontal activity during language generation: Contributions to lexical, semantic, and phonological processes. Journal of the International Neuropsychological Society, 9, 1061-1077.

Crosson, B., Rao, S. M., Woodley, S. J., Rosen, A. C., Bobholz, J. A., Mayer, A., et al. (1999). Mapping of semantic, phonological, and orthographic verbal working memory in normal adults with functional magnetic resonance imaging. Neuropsychology, 13, 171-187.

Crutch, S. J., \& Warrington, E. K. (2005). Abstract and concrete concepts have structurally different representational frameworks. Brain, 128, 615-627.

Damasio, A. R. (1989). Time-locked multiregional retroactivation: A systems-level proposal for the neural substrates of recall and recognition. Cognition, 33, 25-62.

Damasio, H., Grabowski, T. J., Tranel, D., Hichwa, R. D., \& Damasio, A. R. (1996). A neural basis for lexical retrieval. Nature, 380, 499-505.

de Groot, A. M. B. (1989). Representational aspects of word imageability and word frequency as assessed through word association. Journal of Experimental Psychology: Learning, Memory and Cognition, 15, 824-845.

de Groot, A. M. B. (2006). Effects of stimulus characteristics and background music on foreign-language vocabulary learning and forgetting. Language Learning, 56, 463-506. de Groot, A. M. B., \& Keijzer, R. (2000). What is hard to learn is easy to forget: The roles of word concreteness, cognate status, and word frequency in foreign-language vocabulary learning and forgetting. Language Learning, 50, 1-56.

de Groot, A. M. B., \& Poot, R. (1997). Word translation at three levels of proficiency in a second language: The ubiquitous involvement of conceptual memory. Language Learning, 47, 215-264.

Dehaene, S., Le, C. G., Poline, J. B., Le, B. D., \& Cohen, L. (2002). The visual word form area: A prelexical representation of visual words in the fusiform gyrus. NeuroReport, 13, 321-325.

Dehaene, S., Naccache, L., Cohen, L., Bihan, D. L., Mangin, J. F., Poline, J. B., et al. (2001). Cerebral mechanisms of word masking and unconscious repetition priming. Nature Neuroscience, 4, 752-758.

D’Esposito, M., Detre, J. A., Aguirre, G. K., Stallcup, M., Alsop, D. C., Tippet, L. J., et al. (1997). A functional MRI study of mental image generation. Neuropsychologia, 35, 725-730.

Dumay, N., \& Gaskell, M. G. (2007). Sleep-associated changes in the mental representation of spoken words. Psychological Science, 18, 35-39.

Fiebach, C. J., \& Friederici, A. D. (2004). Processing concrete words: fMRI evidence against a specific right-hemisphere involvement. Neuropsychologia, 42, 62-70.

Fletcher, P. C., Frith, C. D., Baker, S. C., Shallice, T., Frackowiak, R. S., \& Dolan, R. J. (1995). The mind's eye-precuneus activation in memory-related imagery. Neuroimage, 2, 195-200.

Fliessbach, K., Weis, S., Klaver, P., Elger, C. E., \& Weber, B. (2006). The effect of word concreteness on recognition memory. Neuroimage, 32, 1413-1421.

Frantzen, D. (2003). Factors affecting how second language Spanish students derive meaning from context. Modern Language Journal, 87, 168-199.

Friederici, A. D., Opitz, B., \& von Cramon, D. Y. (2000). Segregating semantic and syntactic aspects of processing in the human brain: An fMRI investigation of different word types. Cerebral Cortex, 10, 698-705.

Friston, K. J., Josephs, O., Rees, G., \& Turner, R. (1998). Nonlinear event-related responses in fMRI. Magnetic Resonance in Medicine, 39, 41-52.

Friston, K. J., Williams, S., Howard, R., Frackowiak, R. S., \& Turner, R. (1996). Movement-related effects in fMRI time-series. Magnetic Resonance in Medicine, 35, 346-355.

Ganel, T., Gonzalez, C. L., Valyear, K. F., Culham, J. C., Goodale, M. A., \& Kohler, S. (2006). The relationship between fMRI adaptation and repetition priming. Neuroimage, 32, 1432-1440.

Gaskell, M. G., \& Dumay, N. (2003). Lexical competition and the acquisition of novel words. Cognition, 89, 105-132.

Gerlach, C., Aaside, C. T., Humphreys, G. W., Gade, A., Paulson, O. B., \& Law, I. (2002). Brain activity related to integrative processes in visual object recognition: Bottom-up integration and the modulatory influence of stored knowledge. Neuropsychologia, 40, 1254-1267.

Gerlach, C., Law, I., Gade, A., \& Paulson, O. B. (1999). Perceptual differentiation and category effects in normal object recognition: A PET study. Brain, 122, 2159-2170.

Gerlach, C., Law, I., Gade, A., \& Paulson, O. B. (2000). Categorization and category effects in normal object recognition: A PET study. Neuropsychologia, 38, 1693-1703.

Giesbrecht, B., Camblin, C. C., \& Swaab, T. Y. (2004). Separable effects of semantic priming and imageability on word processing in human cortex. Cerebral Cortex, 14, 521-529. 
Gillette, J., Gleitman, H., Gleitman, L., \& Lederer, A. (1999). Human simulations of vocabulary learning. Cognition, 73, 135-176.

Goodglass, H., Hyde, M. R., \& Blumstein, S. (1969). Frequency, picturability and availability of nouns in aphasia. Cortex, 5, 104-119.

Grill-Spector, K., Henson, R., \& Martin, A. (2006). Repetition and the brain: Neural models of stimulus-specific effects.

Trends in Cognitive Sciences, 10, 14-23.

Grossman, M., Koenig, P., DeVita, C., Glosser, G., Alsop, D., Detre, J., et al. (2002). The neural basis for category-specific knowledge: An fMRI study. Neuroimage, 15, 936-948.

Hoenig, K., \& Scheef, L. (2005). Mediotemporal contributions to semantic processing: fMRI evidence from ambiguity processing during semantic context verification. Hippocampus, 15, 597-609.

Ishai, A., Ungerleider, L. G., \& Haxby, J. V. (2000). Distributed neural systems for the generation of visual images. Neuron, 28, 979-990.

Jessen, F., Heun, R., Erb, M., Granath, D. O., Klose, U., Papassotiropoulos, A., et al. (2000). The concreteness effect: Evidence for dual coding and context availability. Brain and Language, 74, 103-112.

Katz, R. B., \& Goodglass, H. (1990). Deep dysphasia: Analysis of a rare form of repetition disorder. Brain and Language, 39, 153-185.

Kiehl, K. A., Liddle, P. F., Smith, A. M., Mendrek, A., Forster, B. B., \& Hare, R. D. (1999). Neural pathways involved in the processing of concrete and abstract words. Human Brain Mapping, 7, 225-233.

Kosslyn, S. M., Pascual-Leone, A., Felician, O., Camposano, S., Keenan, J. P., Thompson, W. L., et al. (1999). The role of area 17 in visual imagery: Convergent evidence from PET and rTMS. Science, 284, 167-170.

Koutstaal, W., Wagner, A. D., Rotte, M., Maril, A., Buckner, R. L., \& Schacter, D. L. (2001). Perceptual specificity in visual object priming: Functional magnetic resonance imaging evidence for a laterality difference in fusiform cortex. Neuropsychologia, 39, 184-199.

Krause, B. J., Schmidt, D., Mottaghy, F. M., Taylor, J., Halsband, U., Herzog, H., et al. (1999). Episodic retrieval activates the precuneus irrespective of the imagery content of word pair associates. A PET study. Brain, 122, 255-263.

Kraut, M. A., Kremen, S., Segal, J. B., Calhoun, V., Moo, L. R., \& Hart, J. (2002). Object activation from features in the semantic system. Journal of Cognitive Neuroscience, 14, $24-36$.

Kroll, J. F., \& Merves, J. S. (1986). Lexical access for concrete and abstract words. Journal of Experimental Psychology: Learning, Memory, and Cognition, 12, 92-107.

Kronbichler, M., Hutzler, F., Wimmer, H., Mair, A., Staffen, W., \& Ladurner, G. (2004). The visual word form area and the frequency with which words are encountered: Evidence from a parametric fMRI study. Neuroimage, 21, 946-953.

Lee, H., Devlin, J. T., Shakeshaft, C., Stewart, L. H., Brennan, A., Glensman, J., et al. (2007). Anatomical traces of vocabulary acquisition in the adolescent brain. Journal of Neuroscience, 27, 1184-1189.

Marshall, J., Pring, T., Chiat, S., \& Robson, J. (1996). Calling a salad a federation: An investigation of semantic jargon: Part I. Nouns. Journal of Neurolinguistics, 9, 237-250.

Martin, A. (2001). Functional neuroimaging of semantic memory. In R. Cabeza \& A. Kingstone (Eds.), The bandbook of functional neuroimaging of cognition. Cambridge, MA: MIT Press.

Martin, A. (2007). The representation of object concepts in the brain. Annual Review of Psychology, 58, 25-45.
Martin, A., Ungerleider, L. G., \& Haxby, J. V. (2000). Category specificity and the brain: The sensory/motor model of semantic representations. In M. S. Gazzaniga (Ed.), The new cognitive neurosciences (pp. 1023-1036). Cambridge, MA: MIT Press.

Martin, A., Wiggs, C. L., Ungerleider, L. G., \& Haxby, J. V. (1996). Neural correlates of category-specific knowledge. Nature, 379, 649-652.

Martin, N., \& Saffran, E. M. (1992). A computational account of deep dysphasia: Evidence from a single case study. Brain and Language, 43, 240-274.

Mechelli, A., Crinion, J. T., Noppeney, U., O’Doherty, J., Ashburner, J., Frackowiak, R. S., et al. (2004).

Neurolinguistics: Structural plasticity in the bilingual brain. Nature, 431, 757.

Mechelli, A., Gorno-Tempini, M. L., \& Price, C. J. (2003). Neuroimaging studies of word and pseudoword reading: Consistencies, inconsistencies, and limitations. Journal of Cognitive Neuroscience, 15, 260-271.

Mellet, E., Tzourio, N., Denis, M., \& Mazoyer, B. (1998). Cortical anatomy of mental imagery of concrete nouns based on their dictionary definition. NeuroReport, 9, 803-808.

Mestres-Missé, A., Camara, E., Rodriguez-Fornells, A., Rotte, M., \& Munte, T. F. (2008). Functional neuroanatomy of meaning acquisition from context. Journal of Cognitive Neuroscience, 20, 2153-2166.

Mestres-Missé, A., Rodriguez-Fornells, A., \& Münte, T. F. (2007). Watching the brain during meaning acquisition. Cerebral Cortex, 17, 1858-1866.

Middleton, F. A., \& Strick, P. L. (2000). Basal ganglia and cerebellar loops: Motor and cognitive circuits. Brain Research Reviews, 31, 236-250.

Nagy, W. E., Anderson, R. C., \& Herman, P. A. (1987). Learning word meanings from context during normal reading. American Educational Research Journal, 24, 237-270.

Nagy, W. E., \& Gentner, D. (1990). Semantic constraints on lexical categories. Language and Cognitive Processes, 5, 169-201.

Nation, I. S. P. (2001). Learning vocabulary in another language. Cambridge: Cambridge University Press.

Noppeney, U., \& Price, C. J. (2002). Retrieval of visual, auditory, and abstract semantics. Neuroimage, 15, 917-926.

Noppeney, U., \& Price, C. J. (2004). Retrieval of abstract semantics. Neuroimage, 22, 164-170.

Paivio, A. (1971). Imagery and verbal processes. New York: Holt, Rinehart, Winston.

Paivio, A. (1986). Mental representations: A dual coding approach. New York: Oxford University Press.

Paivio, A. (2006). Mind and its evolution: A dual coding theoretical approach. Mahwah, NJ: Erlbaum.

Perani, D., Cappa, S. F., Schnur, T., Tettamanti, M., Collina, S., Rosa, M. M., et al. (1999). The neural correlates of verb and noun processing. A PET study. Brain, 122, 2337-2344.

Pexman, P. M., Hargreaves, I. S., Edwards, J. D., Henry, L. C., \& Goodyear, B. G. (2007). Neural correlates of concreteness in semantic categorization. Journal of Cognitive Neuroscience, 19, 1407-1419.

Plaut, D. C., \& Shallice, T. (1993). Deep dyslexia: A case study of connectionist neuropsychology. Cognitive Neuropsychology, 10, 377-500.

Price, C. J., Wise, R. J., \& Frackowiak, R. S. (1996). Demonstrating the implicit processing of visually presented words and pseudowords. Cerebral Cortex, 6, 62-70.

Ryan, L., Nadel, L., Keil, K., Putnam, K., Schnyer, D., Trouard, T., et al. (2001). Hippocampal complex and retrieval of recent and very remote autobiographical memories: 
Evidence from functional magnetic resonance imaging in neurologically intact people. Hippocampus, 11, 707-714.

Sabsevitz, D. S., Medler, D. A., Seidenberg, M., \& Binder, J. R. (2005). Modulation of the semantic system by word imageability. Neuroimage, 27, 188-200.

Saffran, E. M., \& Sholl, A. (1999). Clues to the functional and neural architecture of word meaning. In C. M. Brown \& P. Hagoort (Eds.), The neurocognition of language. New York: Oxford University Press.

Schacter, D. L., Dobbins, I. G., \& Schnyer, D. M. (2004). Specificity of priming: A cognitive neuroscience perspective. Nature Reviews Neuroscience, 5, 853-862.

Schwanenflugel, P. J., \& Shoben, E. J. (1983). Differential context effects in the comprehension of abstract and concrete verbal materials. Journal of Experimental Psychology: Learning, Memory, and Cognition, 9, 82-102.

Schwanenflugel, P. J., \& Stowe, R. W. (1989). Context availability and the processing of abstract and concrete words in sentences. Reading Research Quarterly, 24, 114-126.

Sebastian-Gallés, N., Martí, M. A., Carreiras, M., \& Cuetos, F. (2000). LEXESP: Léxico informatizado del Español. Barcelona: Edicions Universitat de Barcelona.

Seger, C. A. (2006). The basal ganglia in human learning. Neuroscientist, 12, 285-290.

Seger, C. A., \& Cincotta, C. M. (2006). Dynamics of frontal, striatal, and hippocampal systems during rule learning. Cerebral Cortex, 16, 1546-1555.

Simons, J. S., Koutstaal, W., Prince, S., Wagner, A. D., \& Schacter, D. L. (2003). Neural mechanisms of visual object priming: Evidence for perceptual and semantic distinctions in fusiform cortex. Neuroimage, 19, 613-626.

Stern, C. E., Corkin, S., Gonzalez, R. G., Guimaraes, A. R., Baker, J. R., Jennings, P. J., et al. (1996). The hippocampal formation participates in novel picture encoding: Evidence from functional magnetic resonance imaging. Proceedings of the National Academy of Sciences, U.S.A., 93, 8660-8665.

Tamminen, J., \& Gaskell, M. G. (2008). Newly learned spoken words show long-term lexical competition effects. Quarterly Journal of Experimental Psychology (Colchester), 61, 361-371.

Taylor, W. L. (1953). "Cloze" procedure: A new tool for measuring readability. Journalism Quarterly, 30, 415-417.

Thompson, W. L., \& Kosslyn, S. M. (2000). Neural systems activated during visual mental imagery: A review and meta-analyses. In A. W. Toga \& J. C. Mazziotta (Eds.), Brain mapping: The systems (pp. 535-560). San Diego, CA: Academic Press.
Ullman, M. T. (2006). Is Broca's area part of a basal ganglia thalamocortical circuit? Cortex, 42, 480-485.

van Hell, J. G., \& Candia-Mahn, A. (1997). Keyword mnemonics versus rote rehearsal: Learning concrete and abstract foreign words by experienced and inexperienced learners. Language Learning, 47, 507-546.

van Hell, J. G., \& de Groot, A. M. B. (1998a). Disentangling context availability and concreteness in lexical decision and word translation. Quarterly Journal of Experimental Psychology, 51A, 41-63.

van Hell, J. G., \& de Groot, A. M. B. (1998b). Conceptual representation in bilingual memory: Effects of concreteness and cognate status in word association. Bilingualism: Language and Cognition, 1, 193-211.

Vandenberghe, R., Price, C., Wise, R., Josephs, O., \& Frackowiak, R. S. (1996). Functional anatomy of a common semantic system for words and pictures. Nature, 383, 254-256.

Wagner, A. D., Schacter, D. L., Rotte, M., Koutstaal, W., Maril, A., Dale, A. M., et al. (1998). Building memories: Remembering and forgetting of verbal experiences as predicted by brain activity. Science, 281, 1188-1191.

Wallentin, M., Ostergaard, S., Lund, T. E., Ostergaard, L., \& Roepstorff, A. (2005). Concrete spatial language: See what I mean? Brain and Language, 92, 221-233.

Warrington, E. K. (1975). The selective impairment of semantic memory. Quarterly Journal of Experimental Psychology, 27, 635-657.

Warrington, E. K. (1981). Concrete word dyslexia. British Journal of Psychology, 72, 175-196.

Warrington, E. K., \& Shallice, T. (1984). Category specific semantic impairments. Brain, 107, 829-854.

Whatmough, C., Verret, L., Fung, D., \& Chertkow, H. (2004). Common and contrasting areas of activation for abstract and concrete concepts: An H2 $15 \mathrm{O}$ PET study. Journal of Cognitive Neuroscience, 16, 1211-1226.

Wheatley, T., Weisberg, J., Beauchamp, M. S., \& Martin, A. (2005). Automatic priming of semantically-related words reduces activity in the fusiform gyrus. Journal of Cognitive Neuroscience, 17, 1871-1885.

Wiggs, C. L., \& Martin, A. (1998). Properties and mechanisms of perceptual priming. Current Opinion in Neurobiology, 8 , 227-233.

Wise, R. J., Howard, D., Mummery, C. J., Fletcher, P., Leff, A., Buchel, C., et al. (2000). Noun imageability and the temporal lobes. Neuropsychologia, 38, 985-994.

Worsley, K. J., \& Friston, K. J. (1995). Analysis of fMRI time-series revisited-Again. Neuroimage, 2, 173-181. 